\title{
Optimization Models of Pricing Hydro-thermal Trade Based on Energy Economics
}

\author{
Guangjuan Chen, Zhongfu Tan, Jie Zhao, Jianxun Qi, and Li Li \\ Electricity Power Economics Institute, North China Electric Power University, Beijing, \\ 102206, P.R. China \\ guangjuanchen@126.com, tanzhongfu@sina.com.cn
}

\begin{abstract}
An Optimization model of pricing hydro-thermal trade is presented in day-ahead market of electricity, which object is to maximize the social benefit increment. And an algorithm of the model is given using heuristics algorithm. Example indicates that the model and algorithm are feasible.
\end{abstract}

Keywords: Energy economics, Electricity market, Hydro-thermal trade.

\section{Introduction}

At present, the electric power industry of China is in the interim from planned economy to market economy. In China, some investments of electric power construction come from market but electricity market hasn't been come into being yet, which results that power enterprises are self-governed but the power grid is monopolized. On that condition, the government confirms the electricity price and quantity to grid of each power enterprise every year in order to ensure power enterprises' basic income. According to these data, the State Grid Corporation of China contracts with power enterprises. In this way, every enterprise has contract electric quantity, whatever hydropower or thermal, whatever efficient or inefficient. So it often appears that thermal power enterprises are consuming coal to generate electricity while some hydropower enterprises are spilling water [1].

Hydro-thermal trading is a measure to resolve this problem. Some experts also have already started the research working on the problem [2-5]. Lanbing L. and Chongqing K. et al. [2] presented the concept of generation right, whose emphasis was trade mode. Jiangang Y. et al. [3] researched the generation rights trade, but emphasized particularly on option. Yanling W. and Lizi Z. [4, 5] designed three kinds of forms of generation right trade. All of the papers didn't research the problem of pricing hydro-thermal trade.

Based on the object of energy economics, an optimization model of pricing hydro-thermal trading is bought forward aiming at day-ahead trade in the paper. And we put forward an algorithm of the model by heuristics algorithm and give an example. 


\section{Optimization Models of Pricing Hydro-thermal Trade}

Suppose that there are $\mathrm{n}$ thermal power and $\mathrm{m}$ hydropower enterprises in one regional electric market. Each participant's goal is to maximize his profits increment. The dayahead trade is carried out on the day before the electric dispatching center dispatches electric power (EDC) at the way of bidding. The EDC clears the uniform trading price and corresponding electric quantity at the object of maximizing the social profits increment.

\subsection{Optimization Model of Day-Ahead Trade}

In the day-ahead market, the model of maximizing the social profits increment is:

$$
\begin{gathered}
\left(\mathrm{P}_{3}\right) \max \Delta F_{t}=\sum_{t=1}^{l} \sum_{i=1}^{n} \sum_{j=1}^{m}\left(c_{f i t} q_{i j t}-c_{e j t} q_{i j t}\right), \\
\text { s.t. } q_{f i t}=a_{f i t}-b_{f i t} p_{f i t}, \\
q_{e j t}=-a_{e j t}+b_{e j t} p_{f i t} \\
p_{f i t}=p_{e j t}=p_{t} \\
\sum_{i=1}^{n} q_{f i t}=\sum_{j=1}^{m} q_{e j t}=\sum_{i=1}^{n} \sum_{j=1}^{m} q_{i j t}, \\
c_{e}<p_{t}<c_{f}, \\
q_{f i t} \leq Q_{f i t} \\
W_{e j t}+q_{e j t} \leq Q_{e j t}
\end{gathered}
$$

where $\mathrm{q}_{\mathrm{fit}}$ is the purchasing electric quantity, $\mathrm{p}_{\mathrm{fit}}$ is the relevant price, $\mathrm{a}_{\text {fit }}$ and $\mathrm{b}_{\text {fit }}$ are coefficients of the demand function of thermal power enterprise $i$ at $t$ period of time. $\mathrm{q}_{\mathrm{ejt}}, \mathrm{p}_{\mathrm{ejt}}, \mathrm{a}_{\mathrm{ejt}}$ and $\mathrm{b}_{\mathrm{ejt}}$ are the parameters of hydro-power enterprise $\mathrm{j}$ at $\mathrm{t}$ period of time. $\mathrm{q}_{\mathrm{ijt}}$ is the electric quantity that thermal power enterprise i purchases from hydropower enterprise $\mathrm{j}$ at the price $\mathrm{pt}$ at $\mathrm{t}$ period of time. $\mathrm{c}_{\mathrm{fit}}$ is the average cost, $\mathrm{q}_{\mathrm{fit}}$ is the contract electric quantity of thermal power enterprise $i$ at $t$ period of time. $c_{\text {ejt }}$ is the variable cost and $\mathrm{W}_{\text {ejt }}$ is the contract electric quantity of hydropower enterprise $\mathrm{j}$ at $\mathrm{t}$ period of time. And $\mathrm{Q}_{\mathrm{ej}}$ is the maximal electric quantity that hydropower enterprise $\mathrm{j}$ is able to produce at $\mathrm{t}$ period of time. 1 is the number of period of time. $\mathrm{p}_{\mathrm{t}}$ and $\mathrm{q}_{\mathrm{ijt}}$ are decision variables of $\left(P_{1}\right) . i=1,2, \ldots, n . j=1,2, \ldots, m . t=1,2, \ldots, 1$.

\subsection{Algorithm}

The optimization model $\left(\mathrm{P}_{1}\right)$ is solved using heuristics algorithm and the flow of solving $\left(\mathrm{P}_{1}\right)$ is given in Fig. 1 . 


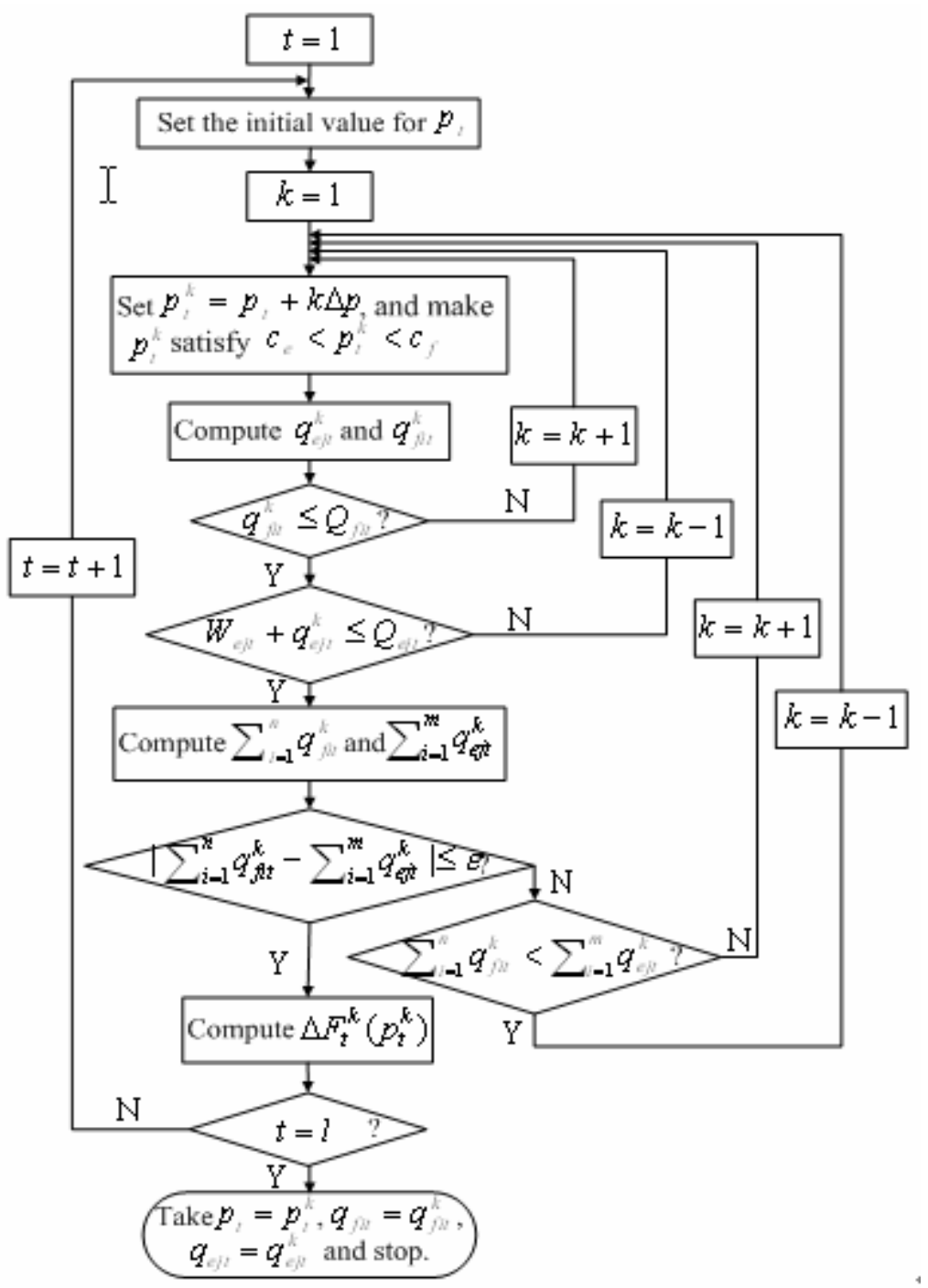

Fig. 1. The figure shows the flow of solving (P3) by using heuristics algorithm

\section{Example}

Suppose that there are three thermal power and two hydropower enterprises who will attend the hydro-thermal trade in one regional electricity market. We choose one period of time of one day to compute. The bidding information is offered in the Tab. 1 . The trade results are given in the Tab. 2. From Table 2, we can see that the uniform clearing price is $62.176 \mathrm{Yuan} / \mathrm{MWh}$ and $270.46 \mathrm{MWh}$ electric quantity is exchanged. 
Table 1. The bidding information of power enterprises in the day-ahead market

\begin{tabular}{ccccccc}
\hline Enterprise & $\begin{array}{c}\text { Trade } \\
\text { Type }\end{array}$ & $\begin{array}{c}\text { Average cost } \\
\text { (Yuan/MWh) }\end{array}$ & $\begin{array}{c}\text { Electric quantity } \\
\text { (MWh) }\end{array}$ & $\begin{array}{c}\text { Maximal quantity } \\
(\mathrm{MWh})\end{array}$ & \multicolumn{2}{c}{$\begin{array}{c}\text { Bidding } \\
\text { coefficient } \\
\text { a }\end{array}$} \\
\hline Thermal a & Buy & 100.00 & 156.25 & 208.33 & 90 & 0.80 \\
Thermal b & Buy & 98.00 & 156.25 & 197.92 & 110 & 0.90 \\
Thermal c & Buy & 91.00 & 166.67 & 218.75 & 100 & 0.95 \\
Hydro a & Sell & 36.00 & 156.25 & 208.33 & 150 & 3.20 \\
Hydro b & Sell & 41.50 & 166.67 & 260.42 & 150 & 3.80 \\
\hline
\end{tabular}

Table 2. The results of the day-ahead trade

\begin{tabular}{ccccc}
\hline Enterprise & $\begin{array}{c}\text { Trade } \\
\text { Type }\end{array}$ & $\begin{array}{c}\text { Price } \\
\text { (Yuan/MWh) }\end{array}$ & $\begin{array}{c}\text { Quantity } \\
\text { (MWh) }\end{array}$ & $\begin{array}{c}\text { The profits } \\
\text { increment (Yuan) }\end{array}$ \\
\hline Thermal a & Buy & & 40.26 & 1522.79424 \\
Thermal b & Buy & & 54.04 & 1935.92896 \\
Thermal c & Buy & 62.176 & 40.93 & 1179.76632 \\
Hydro a & Sell & & 48.96 & 1281.57696 \\
Hydro b & Sell & & 86.27 & 1783.71852 \\
\hline
\end{tabular}

\section{Conclusion}

The hydro-thermal trade can make thermal power and hydropower enterprises gain additional profits. And it can lessen water spill and decrease coal consume.

Acknowledgements. This project is supported by National Natural Science Foundation of China (NSFC) (50579101, 70571023).

\section{References}

1. Quan W., Nianhua X.: Study on the spill electricity price of Central China Power Net. Automation of Electric Power Systems, 7 (2001) 48-51

2. Canbin L., Chongqing K., Qing X. et al: Generation rights trade and its mechanism. Automation of Electric Power Systems, Vol. 27, 6 (2003) 13-18

3. Jiangang Y., Qiliang Z., Jiaqi Z., Pan H.: Generation rights trade mode based on option theory. Proceeding of the CSEE, Vol. 25, 21 (2005) 76-81

4. Yanling W., Lizi Z., Yihan Y.: Adjustiong market of generation rights based on hydrothermal exchange. Proceedings of the CSEE, Vol. 26, 5 (2006) 131-0136

5. Yanling W., Lizi Z.: Design trading market of generation rights. The 7 th International Power Engineering Conference, Vol. 2 (2005) 842-847 